\title{
Erratum to: M. Vrabel and T. Carell for Cycloadditions in Bioorthogonal Chemistry
}

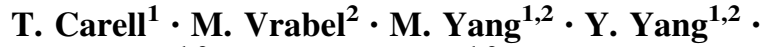 \\ P. R. Chen ${ }^{1,2} \cdot$ J. Dommerholt ${ }^{1,2}$. F. P. J. T. Rutjes ${ }^{1,2}$. \\ F. L. van Delft ${ }^{1,2}$ A. Herner ${ }^{1,2}$ Q Q. Lin ${ }^{1,2}$. \\ H. Wu ${ }^{1,2} \cdot$ N. K. Devaraj ${ }^{1,2} \cdot$ S. Kath-Schorr ${ }^{1,2}$
}

(C) Springer International Publishing Switzerland 2016

\section{Erratum to: Top Curr Chem (Z) (2016) 374:15 DOI 10.1007/s41061-016-0017-3}

The original version of this article unfortunately contained a mistake. The author's portraits were missing. The portraits are given here.

Milan Vrabel

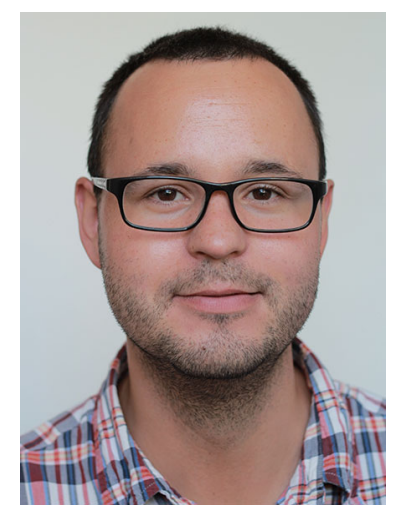

The online version of the original article can be found under doi:10.1007/s41061-016-0017-3.

$凶$ T. Carell

Thomas.carell@cup.uni-muenchen.de

$\bowtie$ M. Vrabel

vrabel@uochb.cas.cz

1 Ludwig-Maximilians University, Butenandtstrasse 5-13, Building F, 81377 Munich, Germany

2 Institute of Organic Chemistry and Biochemistry, AS CR, v.v.i., Flemingovo nam. 2, Building B, 16610 Prague, Czech Republic 
Thomas Carell

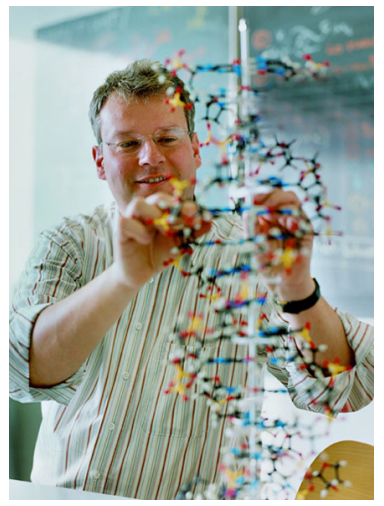

The original article was corrected. 